\title{
What we talk about when we talk about T-cell lymphomas
}

\author{
Han van Krieken
}

Published online: 17 November 2012

(C) Springer-Verlag Berlin Heidelberg 2012

My expectations were high for meeting of the European Association for Haematopathology (EAHP)/Society for Hematopathology last October in Lisbon and I was certainly not disappointed. My experiences with the biannual meeting have always been positive. Interesting key note lectures on aspects of hematopathology from a different angle broadening my views; excellent overviews from experts on the state of the art on specific lymphoma entities, new data from research, and finally many interesting cases in the workshop. And as a bonus, there is a very nice appetizer: the bone marrow day preceding the congress with a similar approach, always excellent. Also this year I was not disappointed.

T-cell lymphoma is obviously an interesting topic, since we know so much less about them compared to B-cell lymphomas. It is a broad topic too! Imagine B-cell lymphoma as a topic, one would immediately think that that is way too broad, yet T-cell lymphomas are even more complex. Nevertheless, the very thoughtful program and the extremely well prepared workshop made it possible to deal with this topic in a very comprehensive way. Actually, I like to mention that in my opinion the panel performance was the best I have ever seen (and I missed only two EAHP meetings).

What are the most important things I have learned? For one, that T-cells are way more versatile and complex than Bcells; and thus that a simple association of a T-cell lymphoma entity with a T-cell of origin is not possible, let alone that a single marker is going to define a T-cell lymphoma entity. Secondly, that the interpretation of the WHO classification by experts is as variable as that of the "real" Bible. Especially the criteria that are used to identify angioimmunoblastic T-cell lymphoma and ALK-negative anaplastic large cell lymphoma really vary. I do look forward to the workshop report and hope that the panel members will shed some additional light here.

In this issue, you will find a workshop report from the 4th Asian Hematopathology Workshop on Epstein-Barr virusassociated $\mathrm{T}$ and $\mathrm{NK}$ cell lymphoproliferative disorders. It is a consensus report in which several interesting proposals for categorizing this complex group of diseases, different from what has been put forward in the WHO classification. As most of you know, T-cell lymphomas are more common in Asia compared to Europe and America. It is very interesting to read on the experiences from this workshop and compared them with those form the EAHP workshop. My conclusion is that it is time for another East meets West meeting, like the one in Hong Kong in 1994. Maybe both panels should take that up.

It is really important that we know what we talk about when we talk about a specific T-cell lymphoma entity, and at present that is not completely the case. But I am optimistic that we are making progress. I do hope that the reports in the Journal of Hematopathology do contribute to this progress.

H. van Krieken $(\bowtie)$

Radboud University Nijmegen Medical Centre, Nijmegen,

The Netherlands

e-mail: J.vanKrieken@pathol.umcn.nl 